\title{
Comparative study of misoprostol sublingually and dinoprostone gel intracervically for cervical ripening and induction of labor
}

\author{
Shikha Yadav*, Nootan Chandwaskar
}

Department of Obstetrics and Gynecology, Sri Aurobindo Medical College and Post-Graduate Institute, Indore, Madhya Pradesh, India

Received: 14 June 2017

Accepted: 08 July 2017

*Correspondence:

Dr. Shikha Yadav,

E-mail: shikhay26@gmail.com

Copyright: () the author(s), publisher and licensee Medip Academy. This is an open-access article distributed under the terms of the Creative Commons Attribution Non-Commercial License, which permits unrestricted non-commercial use, distribution, and reproduction in any medium, provided the original work is properly cited.

\section{ABSTRACT}

Background: Both Prostaglandin E1 and E2 analog are being used for cervical ripening. The aims of study was to compare the efficacy and safety profile of sublingual misoprostol (PGE2) and intracervical dinoprostone (PGE1) for cervical ripening and induction of labor.

Methods: One hundred women with single live fetus and with gestational age of more than 37 weeks admitted for induction of labor were recruited for the study. Patients were randomized to receive either $25 \mu \mathrm{g}$ of misoprostol sublingually or dinaprostone gel $(0.5 \mathrm{mg})$ intracervically.

Results: There was shorter induction to active phase, induction to delivery time intervals and less requirement of oxytocin augmentation in misoprostol group than dinoprostone gel group. Incidence of tachysystole was higher in misoprostol group than dinoprostone gel group (22\% vs $10 \%$ ) however this was not statistically significant. Mode of delivery, maternal and neonatal complications were similar in both the groups.

Conclusions: Use of misoprostol in lower dose is a safe and cost-effective method for cervical ripening and induction of labor.

Keywords: Dinaprostone, Labor Induction, Misoprostol, Prostaglandin

\section{INTRODUCTION}

Induction of labor has become one of the most important tools in an obstetrician's armamentarium. It is done with the aim of achieving vaginal delivery whenever, the continuation of pregnancy presents a threat to the life or wellbeing of the mother and her unborn child. Modern obstetrics technique have greatly increased the safety and reliability of induction of labor so that, it can be performed with greater confidence of success. Timely induction thus reduces the maternal and perinatal morbidity and mortality. ${ }^{1,2}$

Prostaglandin preparations are well known and widely accepted for inducing labor. Dinoprostone which is
Prostaglandin E2 analog is approved drug by Food and drug administration (FDA), USA for the induction of labor, but it is expensive and required refrigeration for its storage. . $^{3,4}$

Moreover additional oxytocin augmentation is required in many patients during induction of labor by dinoprostone. Misoprostol which is a Prostaglandin E1 analog can be administered through vaginal, oral or sublingual routes. It is cost effective and can be stored at room temperature..$^{5}$

The aim of study was to compare the efficacy of sublingual misoprostol tablet $(25 \mu \mathrm{g})$ and intracervical dinoprostone gel $(0.5 \mathrm{mg})$ for cervical ripening and induction of labor. 


\section{METHODS}

One hundred pregnant women with gestation age > 37 weeks with indication of induction of labor visited study center for delivery were randomly chosen selected as subjects for the study. Inclusion criterion was Bishop's score $<6$, Vertex presentation of a single foetus, No cephalopelvic disproportion and with no history of bronchial asthma, glaucoma serious cardiovascular. Patients with known case of glaucoma, haemoglobinopathies and hypersensitivity to prostaglandins, previous uterine surgery, transverse lie or presentation other than cephalic, patients with history of asthma, placenta previa and polyhycdramnios were excluded from the study.

All subjects equally divided into two equal halves. Onehalf of 50 pregnant women who had received $25 \mu \mathrm{g}$ misoprostol tablet which was placed sublingually under the guidance treated as group PGE1 while other half of 50 pregnant women who had received $0.5 \mu \mathrm{g}$ dinoprostone gel in the cervical canal treated as group PGE2.

All the recruited women were explained about the complete treatment procedure in their own language and her willingness to undergo the treatment and to participate in the study had recorded in a consent form dually signed by her. Detail history of the patient was recorded with special reference to age, parity, menstrual history and obstetrical history. Gestational age was calculated from the first day of last menstrual cycle and ultrasonography. Taking all aseptic precautions per vaginal examination was done. Pelvis was assessed, cervical status was recorded specially the position, length, consistency and effacement of the cervix is noted along with the descent of the presenting part the prediction of inducibility can be done by cervical scoring which was introduced by Bishop.

Under full aseptic measures Sims vaginal speculum was applied and cervix was visualized. The catheter of preloaded PGE2 gel (Dinoprostone $0.5 \mathrm{mg}$ ) syringe was then introduced under vision into the cervical canal. The catheter was then advanced upto the internal Os and then slightly withdrawal. While slowly withdrawing the catheter, the plunger was slowly pushed to instill the contents into the cervical canal.

The patient was asked to remain supine for at least 30 minutes after gel administration after 6 hours oxytocin drip was started till patient developed an adequate uterine contraction pattern ( 3 or more uterine contractions in 10 minutes lasting more than 40 seconds), the cervix reached $4 \mathrm{~cm}$ or more of dilatation and $100 \%$ effacement or spontaneous rupture of membranes.

Patients in Misoprostol group received $25 \mu \mathrm{g}$ misoprostol tablet which was placed sublingually under the guidance.
Subsequent doses were given after every 3 hours till patient developed an adequate uterine contraction pattern.

In both groups all the patients were 'observed for initiation of contractions by palpating uterus perabdomen auscultation of foetal heart rate by stethoscope or Doppler. Effacement and dilatation of cervix, condition of membranes, position of presenting part by pervaginal examination. Pulse rate, blood pressure, fever recorded. Record of following side effects was kept as vomiting, diarrhoea, nausea, tachycardia, bronchial spasm, tachysystole, hypertonus, foetal heart rate abnormalities, passage of meconium.

Subjects in group PGE1 (Misoprostol group) were compared with subjects in group PGE2 (Dinoprostone group) in order to identify the efficacy of used means for pre-induction cervical ripening and induction of labor and to compare the effectiveness and safety of sublingual misoprostol as compared to dinoprostone gel.

\section{RESULTS}

A total of 100 subjects randomly selected for study. In group PGE1, 56.0\% subjects were primigravida while $62.0 \%$ in group PGE2 included for present study. The age of all subjects in both the groups were obtained with a minimum of 18 years while the maximum age was 37 years. There was no significant difference in mean age and mean Bishop Score at admission in both groups (Table 1).

Table 1: Comparison of different variables in sublingual misoprostol and dinoprostone gel.

\begin{tabular}{|llll|}
\hline Age & PGE1 group & PGE2 & P value \\
\hline $\begin{array}{l}\text { Bishop } \\
\begin{array}{l}\text { Score at } \\
\text { admission }\end{array}\end{array}$ & $2.84 \pm 0.95$ & $3.30 \pm 1.87$ & 0.094 \\
\hline $\begin{array}{l}\text { Active phase } \\
\text { interval }\end{array}$ & $1.71 \pm 1.23$ & $5.47 \pm 3.31$ & $<0.0001$ \\
\hline $\begin{array}{l}\text { Induction to } \\
\text { delivery } \\
\text { interval }\end{array}$ & $5.39 \pm 2.97$ & $10.88 \pm 7.33$ & $<0.0001$ \\
\hline $\begin{array}{l}\text { Oxytocin } \\
\text { requirement }\end{array}$ & $11(22 \%)$ & $33(66 \%)$ & $<0.0001$ \\
\hline $\begin{array}{l}\text { Tachysystole } \\
\text { APGAR score }\end{array}$ & $11(22 \%)$ & $5(10 \%)$ & 0.102 \\
\hline $\begin{array}{l}\text { at 1min } \\
\text { APGAR score }\end{array}$ & $7.64 \pm 2.41$ & $5.84 \pm 2.28$ & 0.6708 \\
\hline \begin{tabular}{l} 
at 5min \\
\hline
\end{tabular} & $7.68 \pm 3.03$ & 0.6085 \\
\hline
\end{tabular}

Table 2 showed that the postdatism was most common indication of induction of labor in groups but observed more in PGE2 $(40.0 \%)$ as compared to group PGE1 (30.0\%) followed by Pre-eclampsia was found in $14.0 \%$ and $12.0 \%$ in groups PGE2 and PGE1 respectively. Incidences of eclampsia was noted in $8.0 \%$ was lower in group PGE1 in comparison to groups PGE2 was in $14.0 \%$. 
Table 2: Indication of induction of labor.

\begin{tabular}{|lllll|}
\hline & $\begin{array}{l}\text { Misoprostol } \\
\text { Indication }\end{array}$ & \multicolumn{2}{l|}{$\begin{array}{l}\text { Cerviprime } \\
\text { (PGE1) }\end{array}$} & \multicolumn{2}{l|}{ Gel (PGE2) } \\
\hline Postdatism & 15 & 30.0 & 20 & 40.0 \\
\hline Eclampsia & 4 & 8.0 & 7 & 14.0 \\
\hline Pre-eclampsia & 6 & 12.0 & 7 & 14.0 \\
\hline IUD & 4 & 8.0 & 5 & 10.0 \\
\hline Abruption (PIH) & 1 & 2.0 & 1 & 2.0 \\
\hline Oligo & 1 & 2.0 & 5 & 10.0 \\
\hline Prolonged first stage & 2 & 4.0 & 2 & 4.0 \\
\hline IUGR & 4 & 8.0 & 2 & 4.0 \\
\hline PROM & 12 & 24.0 & 0 & 0.0 \\
\hline Congenital anomaly & 1 & 2.0 & 1 & 2.0 \\
\hline
\end{tabular}

Labor was considered established if patient had 3 or more uterine contractions in 10 minutes and dilatation of cervix was $>4 \mathrm{~cm}$. The average interval from start of medication to established labor was $1.71 \pm 1.23$ hours in PGE1 group and 5.47 \pm 3.31 hours in PGE2 group $(\mathrm{p}<0.05)$ that was statistically significant. In group PGE1, $80 \%$ of the women attained the labor within 4 hours of medication which is much higher than PGE2 group in which only $18 \%$ of subjects attained labor with 4 hours (Table 3 ).

Table 3: Induction: active phase interval.

\begin{tabular}{|lll|}
$\begin{array}{l}\text { Active phase } \\
\text { Interval } \\
\text { (hours) }\end{array}$ & $\begin{array}{l}\text { Misoprostol } \\
\text { (PGE1) }\end{array}$ & $\begin{array}{l}\text { Dinoprostone } \\
\text { Gel (PGE2) }\end{array}$ \\
\hline$<4$ & $\mathbf{n = 5 0}$ & $\mathbf{n = 5 0}$ \\
\hline $4-8$ & $40(80 \%)$ & $9(18 \%)$ \\
\hline$>8$ & $10(20 \%)$ & $28(56 \%)$ \\
\hline
\end{tabular}

The mean induction delivery interval (IDI) was also shorter in the PGE1 group as compared to PGE2 group (5.39 \pm 2.97 hours vs. $10.88 \pm 7.33$ hours respectively). 94\% patients in PGE1 group and $60 \%$ patients in PGE2 group delivered the baby within 12 hours in present study $(\mathrm{P}<0.0001)$.

Table 4: Induction to delivery interval.

\begin{tabular}{|lll|}
$\begin{array}{l}\text { Induction to } \\
\text { delivery interval } \\
\text { (hours) }\end{array}$ & $\begin{array}{l}\text { Misoprostol } \\
\text { (PGE1) }\end{array}$ & $\begin{array}{l}\text { Dinoprostone } \\
\text { Gel (PGE2) }\end{array}$ \\
\hline$<12$ & $\mathbf{n = 5 0}$ & $\mathbf{n = 5 0}$ \\
\hline $12-24$ & $47(94 \%)$ & $30(60 \%)$ \\
\hline$>24$ & $03(06 \%)$ & $17(34 \%)$ \\
\hline
\end{tabular}

Oxytocin requirement for augmentation was significantly higher in subjects treated with PGE2 as compared to sublingual PGE1 $(\mathrm{P}<0.0001)$.

Tachysystole was developed more $(22.0 \%)$ in subjects treated with sublingual misoprostol (group PGE1) than in subjects treated with dinoprostone gel (10\%). Tachysystole was defined as 6 or more uterine contractions in 10 minutes for 2 consecutives 10 minute's periods. However, the difference was statistically insignificant $(p=0.173)$. In patients who developed tachysystole isoxsuprine HCL drip was started (up to maximum of $0-12 \mathrm{mg} / \mathrm{min}$ ).

The mode of delivery was most commonly vaginal in both the groups $(88.0 \%$ in PGE1 and $74.0 \%$ in PGE2). Fetal Distress was measured in $16.0 \%$ was more in group PGE2 as compared to $6.0 \%$ in group PGE1. The Cesarean section was noted in few $(6.0 \%$ and $10.0 \%)$ in groups PGE1 and PGE2 respectively. The mode of delivery was found to be not associated significantly with subjects treated with PGE1and PGE2. No maternal complications were seen in subjects treated with sublingual misoprostol whereas nausea (4.0\%), vomiting $(4.0 \%)$ and $\mathrm{PPH}(6.0 \%)$ was identified as maternal complications in subjects treated with dinoprostone gel in group PGE2.

Table 1 projected that neonatal APGAR score at 1 minute and 5 minute. The neonatal APGAR scores at 1 and 5 minute in subjects were found significantly similar in subjects treated either with sublingual Misoprostol or dinoprostone gel.

Table 5: Neonatal complications.

\begin{tabular}{|lllll|}
\hline $\begin{array}{l}\text { Maternal } \\
\text { complication }\end{array}$ & $\begin{array}{l}\text { Misoprostol } \\
\text { (PGE1) }\end{array}$ & \multicolumn{2}{l|}{$\begin{array}{l}\text { Dinoprostone } \\
\text { gel (PGE2) }\end{array}$} \\
\hline Hyperbilirubinemia & 4 & $\mathbf{\%}$ & $\mathbf{n}$ & $\mathbf{\%}$ \\
\hline Septicemia & 2 & 4.0 & 4 & 8.0 \\
\hline IUFD & 1 & 2.0 & 0 & 0.0 \\
\hline IUFD, MSB & 3 & 6.0 & 0 & 0.0 \\
\hline IUFD, FSB & 2 & 4.0 & 2 & 4.0 \\
\hline FSB & 0 & 0.0 & 3 & 6.0 \\
\hline None & 38 & 76.0 & 40 & 80.0 \\
\hline Total & 50 & 100.0 & 50 & 100.0 \\
\hline
\end{tabular}

Few neonatal complications were observed in both the groups. Incidence of hyperbilirubinemia was most common $(8.0 \%)$ in both the groups (Table 5). Septicemia, IUFD, IUFD with MSB, IUFD with FSB, FSB was identified as neonatal complications in both the groups (PGE1 and PGE2).

\section{DISCUSSION}

The ideal agent for cervical ripening and induction of labor should be effective, non-invasive, economical rapid in action and safe to both mother and fetus. None of the methods or agents currently available fulfill all these criteria, but prostaglandins are one of the most effective means of achieving cervical ripening and induction of labor providing, good clinical efficacy and patient satisfaction. FIGO has given his recommendation for the use of intravaginal Misoprostol $(25 \mu \mathrm{g} 4$ hourly for 
maximum six dosages) for induction of labor at term. ${ }^{6}$ Therefore Misoprostol can be such an agent with the advantages of cost and convenience, despite of the fact that it is not FDA-labelled for this purpose. Praveen et al done comparative studies of sublingual (S/L), oral and vaginal misoprostol for cervical ripening and reported that administration of misoprostol by the sublingual route is better than the oral and vaginal routes for cervical ripening. ${ }^{7}$ Therefore in this study we compare sublingual misoprostol with intracervical dinoprostone gel in cervical ripening and induction of labor.

Patients receiving sublingual administration of misoprostol have shorter induction to active phase, induction to delivery time intervals and also require less oxytocin for augmentation than the patients in which intra cervical dinoprostone gel was administered. Similar to present study Wing et al, McKenna et al, Liu et al, and Jha et al reported shorter IDI in Misoprostol group than in Dinoprostine group. ${ }^{8-11}$ However Zhang et al did not find significant difference in IDI in two groups. ${ }^{12}$

Similar to present study Zhang et al reported higher rate of tachysystole in women receiving misoprostol than in those receiving PGE2 gel. ${ }^{12}$ APGAR score at 1 minute and at 5 minute as well as neonatal complications was statistically similar in both the groups. Liu et al, Langenegger et al and Patil et al also reported the same. ${ }^{10,13,14}$

It is demonstrated to be a viable alternative technique of labor induction since it is efficacious, easily administered, not expensive, stable at room temperature, needs no refrigeration with a longer shelf-life than dinoprostone gel. It allows the better patient acceptability although uterine hyper stimulation and meconium staining is the main concern with misoprostol use, close maternal-foetal monitorization and timely intervention measures would prevent devastating adverse effects during labor induction and increase tolerability of the drug by both the mother and foetus. So, by the present study, it was concluded that sublingual misoprostol is a more successful, lower-cost agent for induction of labor than intracervical dinoprostone gel.

Funding: No funding sources Conflict of interest: None declared

Ethical approval: The study was approved by the Institutional Ethics Committee

\section{REFERENCES}

1. Gulmezoglu AM, Crowther CA, Middleton P. Induction of labor for improving birth outcomes for women at or beyond term. Cochrane Database Syst Rev. 2006;(4):CD004945.
2. Stock SJ, Ferguson E, Duffy A, Ford I, Chalmers J, Norman JE. Outcomes of elective induction of labor compared with expectant management: population based study. BMJ. 2012;10:344:e2838.

3. Witter FR. Prostaglandin E2 preparations for preinduction cervical ripening. Clin Obstet Gynecol. 2000;43:469-74.

4. Thomas J1, Fairclough A, Kavanagh J, Kelly AJ. Vaginal prostaglandin (PGE2 and PGF2a) for induction of labor at term. Cochrane Database Syst Rev. 2014;(6):CD003101.

5. Tang OS, Gemzell-Danielsson K, Ho PC Misoprostol: pharmacokinetic profiles, effects on the uterus and sideeffects. Int J Gynecol Obstet. 2007;99(2):S160-7.

6. Weeks A, Faúndes A. Misoprostol in obstetrics and gynecology. Int J Gynecol Obstet. 2007;99(2):S156-9.

7. Parveen S, Khateeb ZA, Mufti SM, Shah MA, Tandon VR, Hakak S et al. Comparison of sublingual, vaginal, and oral misoprostol in cervical ripening for first trimester abortion. Indian J Pharmacol. 2011;43(2):1725 .

8. Wing DA, Rahall A, Jones MM, Goodwin TM, Paul RH. Misoprostol: an effective agent for cervical ripening and labor induction. Am J Obstet Gynecol. 1995;172(6):1811-6.

9. McKenna DS, Ester JB, Proffitt M, Waddell KR. Misoprostol outpatient cervical ripening without subsequent induction of labor: A randomized trial. Obstet Gynecol. 2004;104(3):579-84.

10. Liu A, Lv J, Hu Y, Lang J, Ma L, Chen W. Efficacy and safety of intravaginal misoprostol versus intracervical dinoprostone for labor induction at term: a systematic review and meta-analysis. J Obstet Gynaecol Res. 2014;40(4):897-906.

11. Jha N, Sagili H, Jayalakshmi D, Lakshminarayanan S. Comparison of efficacy and safety of sublingual misoprostol with intracervical dinoprostone gel for cervical ripening in prelabor rupture of membranes after 34 weeks of gestation. Arch Gynecol Obstet. 2015;291(1):39-44.

12. Zhang Y, Wang J, Yu Y, Xie C, Xiao M, Ren L. Misoprostol versus prostaglandin E2 gel for labor induction in premature rupture of membranes after 34 weeks of pregnancy. Int $\mathbf{J}$ Gynecol Obstet. 2015;130(3):214-8.

13. Langenegger EJ, Odendaal HJ, Grove D. Oral misoprostol versus intracervical dinoprostone for induction of labor. Int J Gynecol Obstet 2005;88:242-8.

14. Patil KP, Swamy MK, Rao RK. Oral misoprostol vs intra-cervical dinoprostone for cervical ripening and labor induction. J Obstet Gynecol India. 2005;55(2):128-131.

Cite this article as: Yadav S, Chandwaskar N. Comparative study of misoprostol sublingually and dinoprostone gel intracervically for cervical ripening and induction of labor. Int J Reprod Contracept Obstet Gynecol 2017;6:3624-7. 